American Research Journal of English and Literature

ISSN (Online): 2378-9026

Volume 4, Issue 1, 2018, 1- 6 Pages

DOI:10.21694/2378-9026.18008

AMERICAN RESEARCH JOURNALS

An Academic Publishing House

\title{
The Nature of Meaning
}

Acheoah, John Emike (PhD), Olaleye, Joel Iyiola (PhD)

Department of European Languages, Federal University, Birni-Kebbi, Nigeria

Department of English, Waziri Umar Federal Polytechnic, Birnin-Kebbi, Nigeria

actualemike@gmail.com

Abstract: This paper examines meaning in language. It is therefore a study in semantics. Semantics is the study of meaning in terms of the linguistics. Semantics begins from the stopping point of syntax and ends from where pragmatics begins. A separate discipline in the study of language, semantics has existed for decades. The term semantics was first used by Breal in 1987 and it does not suggest that there had never been speculations about the nature of meaning (Ogbulogo (2005). Words, phrases and sentences are used to convey messages in natural languages. Semantics is the study of meaning systems in language. If meaning is a system, then language is systematic in nature. In this paper, we investigate the nature of meaning to locate the significance of semantics in contemporary linguistics. Frege, cited in Sandt (1988:1) rightly notes that "... [If] anything is asserted there is always an obvious presupposition that the simple or compound proper names used have reference." Hinging on different submissions in the literature, we conclude that meaning is: socio-cultural, dynamic, grammar-driven, conventional, representative (referential), individualistic (non-conventional) and is not exhaustive.

Keywords: Semantics, meaning, language, linguistics

\section{INTRODUCTION}

In all human languages, meaning is a crucial component. Fodor (1977:7) rightly notes that "the study of meaning has a long history..." Although the world's languages have certain universal properties, the study of language peculiarities still abound in contemporary linguistics. Gilbert Lazard (2004:394-395) posits that "a language is a system of potentialities. Practically each grammatical or lexical unit has a whole range of potential uses... All linguistic units are supposed to assume a precise meaning (except in case of intentional or fortuitous ambiguity) and, last but not least, they often have a specific reference." In this paper, our aim is to investigate the nature of meaning (the semantics of natural languages). "Semantics is the study of meaning" (Lyons, 1977). For Hurford and Heasley (1983), "semantics is the study of meaning in language." Other scholars define semantics with different or similar perspectives. For example, Saeed (1997) opines that "semantics is the study of meaning communicated through language." According to Lobner (2002), "semantics is the part of linguistics that is concerned with meaning." Kreidler's (1998) definition is also useful: "Linguistic semantics is the study of how language organizes and express meaning." Indeed, more definitions of semantics will continue to evolve in the literature as the subject gets expanding research attention in contemporary linguistics.

\section{THEORETICAL ISSUES}

Scholars believe that semantics is not prescriptive; that is, it is not concerned with laying down standards of semantic correctness or prescribing what the meaning of words and sentences shall be. Rather, the aim of semantics is to evolve theories that facilitate the understanding of the nature of meaning.

\section{Theories of Meaning}

John T. Kearns, cited in Savas L. T. (1994:72) posits that "syntactic theories in linguistics are certainly semantically motivated. Otherwise they would have no occasion to assign different structures to a single sentence (to a 
single sentential string of words). But these theories can be interpreted in different ways. They can be regarded as systems of representations of linguistic acts/activities, showing both semantic structures and syntactic characters of an abstract level. Or they can be conceived as theories of the syntactic characters of abstractly conceived linguistic acts/activities." Theories of meaning are as follows:

\section{Meaning as Object}

This theory posits that the meaning of a word is its referent. The theory corroborates Alston (1964), cited in Adeyemi (2000:46-47) who posits that "the meaning of a word is the idea that the word brings forth in the speaker or hearer. It is assumed that in uttering a word, some idea, exists in the mind of the speaker and his uttering the word will evoke the same idea in the mind of the hearer." In a similar vein, Frege (1997:163) submits that "a logically perfect language should satisfy the conditions that every expression grammatically well constructed as a proper name out of signs already introduced shall in fact designate an object, and that no new sign shall be introduced as a proper name without being secured a reference." Fodor (ibid.:11) opines that "the theory that meanings are ideas implies that the compositionality of meanings should be accounted for in terms of the compositionality of ideas." Fodor adds that "... to know the meaning of a word is to have a certain idea associated with it, or, on the behavioural theory, that to know the meaning of a word is to be conditioned to respond to utterances of it in a certain fashion" (ibid.:14). However, Fodor contends that it is crucial to define precisely what counts as idea to avoid ambiguity in the use of the term. It is interesting to note that "the whole theory of reference since Frege is mistaken in supposing that we come to reality with a prior inventory of objects already given, and that is not true. We have to decide what we are going to count as an object, and then given a language we can have all kinds of objects that we cannot have without language, such as the meeting, or the party, or the election" (Searle, cited in Jozsef 2011:132).

\section{Meaning as Mental Image}

According to this theory, the meaning of a word is the mental image it conjures). Adeyemi (ibid::46) asserts that "the Image Theory of Meaning reduces the meaning of a word to a question of the image the word calls forth in the hearer's or speaker's mind."

\section{Meaning as Semantic Primes}

The meaning of a word is its semantic components. Thus, words have sense elements.

\section{Meaning as Use}

The meaning of an expression is the action it is used to perform; that is, its pragmatic potentials.

\section{The Contextual Theory of Meaning}

This theory was popularized by Firth J. R. whose views dominated British linguistics until his death. In explicating this theory, Firth asserts that "the most vital fact about language is its social function" (cited in Adeyemi, ibid.:48).

One can have significant insights on the nature of meaning if one considers types of meaning or semantic relations discussed below:

\section{Connotation}

This is the company that words keep. For example, the word terrorism can evoke the word bomb, yet, terrorism does not mean bomb.

\section{Denotation}

This is the conventional (dictionary) meaning of a word. 


\section{Synonymy}

This is when words have similar meaning e.g. strike/hit.

\section{Antonymy}

This is when two words have opposite meaning e.g. stand/sit.

\section{Polysemy}

This is when a word has two or more meanings e.g. deposit (earth's mineral/money in bank).

\section{Paraphrase}

Two sentences are paraphrases of each other if they can have the same meaning e.g.:

Iyowame and Itofame ate rice.

Rice was eaten by Iyowame and Itofame.

Indeed, a thorough investigation of semantics is useful for understanding meaning. It should be noted that like in other fields of linguistics, semantic postulations (theories) are bedeviled by controversies. For example, although Meaning Postulate posits that "the meaning of each word is said to be dictated by the semantics or postulate in which it can occur or with which it can be associated", critics believe that the theory is lexemedependent, and disregards the pragmatic constrains which inform language use in communicative events. Also, the theory does not have correct explanation for the relations between syntax and semantics as in sentences where meaninglessness, ambiguity and contextual use are evident. Consider:

\section{The hunter killed the snake.}

The snake killed the hunter.

But for Levinson (1983), “Carnap's 'Meaning Postulate' helps explain effective inferencing. The concept states the analytical equivalences not captured elsewhere in a semantical system but with additional reference to contextual factors. Thus an inference rule was suggested that states that if a speaker says "Can you VP? (or any other expression of the same concepts) in a context in which a question reading could not be intended, then his utterance would be equivalent to his having said "I request you to VP." Altson (1964) also notes that "... anything to which we can refer can be referred to by many expressions."

One cannot describe the nature of meaning successfully without mentioning the role of context. Defining meaning from the perspective of context of language and response to such context-driven language use, Bloomfeild analyses the context (situation) of an utterance into three constituent parts:

A - speaker's stimulus;

B - utterance (= speaker's response and hearer's stimulus);

C - hearer's response;

Going by this scheme, stimulus are compulsory informants of speakers' utterance. A speaker's utterance will act as a stimulus to the hearer who will in turn make a response. Nevertheless, meaning cannot be reduced to stimulus in some cases (response connection). Popularizing the Contextual Theory of Meaning, Firth J.R., whose views dominated British Linguistics until his death, asserts that the most vital fact about language is its social function. He posits that every utterance is actualized in a culturally determined 'context of situation', and the meaning of an utterance is the totality of all the features in it that can be singled out as giving input to the maintenance of the patterns of life in the society in which the speaker lives. 
Within the scope of this study, we cannot exhaust the critical submissions in the literature; submissions which give us interesting perspectives on the nature of meaning. First and foremost, there are scholars who hold the view that actions, not expressions, carry meaning. However, because words (expressions) constitute word classes (parts of speech), they have syntactic features - there are conventional grammar principles for patterning expressions to perform meaningful acts such as making statements, asking questions, etc. It should be noted that flouting the rules of grammar does not mean language users cannot perform meaningful linguistic acts. This is why scholars contend for a syntactic-semantic theory for the elucidation of natural language. Indeed, grammar functions in the meaning system of human languages. According to Fodor (ibid.:4), "... the meaning of a sentence is a function of the morphemes it contains and the way in which those morphemes are syntactically combined." In addition, Fodor (ibid.:6) reports that "there are also linguists who maintain that the semantic component of a grammar, is empty and that the deep structures of sentences themselves constitute adequate representations of meaning, so that the relation between deep structure and meaning is simply that of identity."

Expressions can readily be evolved to name whatever practice or object that gets into the society. "The need to designate new things, persons, places and concepts is, obviously, a universal cause of lexical innovation" (Weinrich, (1953:56).

The interpretation of meaning continues to be dependent on human and extra-linguistic factors. This situation makes the study of meaning an endless endeavour. Traugott proposed three major tendencies of semantic change. These are:

(1) Tendency I: Meanings based in the external described situation > meanings based in the internal evaluative/ perceptual/cognitive) described situation

(2) Tendency II: Meanings based in the external or internal described situation > meanings based in the textual and metalinguistic situation

(3) Tendency III: Meanings tend to become increasingly based in the speaker's subjective belief state/attitudes towards the proposition (Traugott (1989:34-5). Traugott (ibid.:256) also notes that "if there occurs a meaning shift which, in the process of grammaticalization, entails shifts from one functional-semantic component to another, then such a shift is more likely to be from propositional through textual to expressive than in the reverse direction."

While some scholars view meaning in terms of the situation of an utterance, others view meaning in terms of the truth-value of utterances. Levinson (ibid.) submits that "there are two main classes of semantic theories available to linguists at the present time. One is the truth-conditional class of theories. The other is the class that assumes that all semantic relations are definable in terms of translations of sentences into atomic concepts or semantic features." According to Bloomfeild (1933), "the meaning of a linguistic form is the situation in which the speaker utters it, and the response which it calls forth in the hearer." For Kempson (1977:73f), "a semantic theory ... will assign interpretation to sentences where these interpretations are for each sentence a set of conditions necessary and sufficient for the truth of that sentence."

Indeed, meaning remains a phenomenon subject to unending definitions. A single expression may not sufficiently describe an object or phenomenon as noted by Thomas Carlyle, cited in William O' Grady (1994:174) who posits that "... in every object there is inexhaustible meaning."

\section{Discussion AND CONCLUSION}

Language research expands in contemporary time. "Language is integrated into our behaviour and our interactions with others in an intimate way. We USE it, to give commands, to answer questions, to greet each other, to argue, and so on. Language should be viewed not as an abstract calculus but as a tool, and just like a hammer or a can opener, the proper characterization of a linguistic expression must include an account of how 
it is used and what it is used for" (Fodor, ibid.:19). Representation is very central to the nature of meaning as seen in stretches. According to Fodor (ibid.:80), "once syntactic structures are allowed to contain universal semantic elements as their terminal symbols, the syntactic deep structures of sentences can serve as their semantic representations. The interpretive semantic component can be dispensed with entirely - hence the name 'generative semantics'. The derivation of a surface structure begins with the generation of a semantic representation which is simultaneously a syntactic deep structure and this is then mapped by the successive application of syntactic transformations onto a surface structure. There is no LEVEL of structure, like the standard level of deep structure, which mediates the correlation of semantic representations with surface structures. The rules which operate on structures containing semantic elements are claimed to have exactly the same general formal properties as the same general formal properties as the more familiar syntactic transformations which apply at later stages of derivations." Interestingly,

Chomsky, cited in Fodor (ibid.:81) points out that “... constructions which are assigned identical underlying structures in generative semantic grammars exhibit significant syntactic differences which cannot naturally be captured by a difference of transformational derivation but only by a difference of deep structure."

The potency of words to mean is dependent on the fact that they express phenomena in natural languages when used in stretches. This fact explains theories of presuppositions and truth-conditional semantics. Paul Simpson (2004:7) opines that "a semantic analysis is concerned with meaning and will be interested, amongst other things, in those elements of language which give the sentence a 'truth value'. A truth value specifies the conditions under which a particular sentence may be regarded as true or false." Paul Simpson (ibid.:7) also notes that "... what a sentence 'means' in strictly semantic terms is not necessarily a guarantor of the kinds of job it will do as an utterance in discourse."

As research in semantics increases, the nature of meaning becomes more fascinating. In this paper, we conclude that although the description of the concept, meaning, is not exhaustive, it is clear that meaning is systematic, dynamic, referential, typological, resident in language, compositional, socio-cultural, contextual/situational, stimulus-response generating, grammar-driven and not exhaustive.

\section{REFERENCES}

1. Adeyemi, O. Babajide. Ed. (2000). Studies in English Language. Ibadan: Enicrownfit Publishers.

2. Bloomfield, L. (1933). Language. New York.

3. Firth, J. R. (1957). Papers in Linguistics, 1934-1951. London: Oxford University Press.

4. Firth, J. R. (1962). "A Synopsis of Linguistic Theory" in Studies in Linguistic Analysis. London: Philosophical Society, pp.1930-1935.

5. Fodor, J. D. (1977). Semantics: Theories of Meaning in Generative Grammar. England: John Spiers.

6. Frege, G. (1997). The Frege Reader. Oxford; UK; Cambridge, Mass: Blackwell Publishing.

7. Gilbert, Lazard (2004). On the Status of Linguistics with Particular Regard to Typology. The Linguistic Review 21, 389-411.

8. Jozsefe Andor (2011). Reflections on Speech Act Theory: An Interview with John R. Searle. International Review of Pragmatics 3:113-134.

9. Kempson, R. (1977). Semantic Theory. New York: Cambridge University Press.

10. Kreidler Charles W. (1998). Introducing English Semantics. London: Routledge. 
The Nature of Meaning

11. Levinson, Stephen. (1983). Pragmatics. Cambridge: Cambridge University Press.

12. Lobner, Sebastian (2002). Understanding Semantics. Arnold: London: Blackwell.

13. Lyons, John (1977). Semantics, Vol.1 Cambridge: Cambridge University Press.

14. Ogbulogo C. (2005). Concepts in Semantics. Lagos: Sam Iroanusi Publications.

15. O' Grady, W. (2004). "Semantics: The Analysis of Meaning” in O' Grady, William and Archibald, John eds. Contemporary Linguistic Analysis: An Introduction. Canada: Pearson Education.

16. Saeed, John I. (1997). Semantics. Oxford: Blackwell.

17. Sandt, R. A. van der. (1988). Context and Presupposition. London: Croom Helm.

18. Savas, L. Tsohatzidis Ed. (1994). Foundations of Speech Act Theory. London: Routledge.

19. Traugott, Elizabeth C. (1989). On the Rise of Epistemic Meanings in English: An Example of Subjectification in Semantic Change. Language 65(1):31-55.

20. Uriel Weinreich (1974). Language in Contact: Findings and Problems. The Hague: Monton \& Co. N.V.

Citation: Acheoah, John Emike, Olaleye, Joel Iyiola, "The Nature of Meaning" American Research Journal of English and Literature, vol 4, no. 1, 2018, pp. 1-6.

Copyright (c) 2018 Acheoah, John Emike, Olaleye, Joel Iyiola, This is an open access article distributed under the Creative Commons Attribution License, which permits unrestricted use, distribution, and reproduction in any medium, provided the original work is properly cited. 